\title{
Imunomodulador P-MAPA: Nova Perspectiva Terapêutica Frente à Modulação do Sistema Imune no Câncer Pancreático Quimicamente Induzido em Ratos
}

\author{
Natália C. Siqueira*, Eduardo A. R. Socca, Nelson Durán, Wagner J. Fávaro.
}

\section{Resumo}

O câncer de pâncreas (CP) constitui um dos tumores mais agressivos, sendo responsável por $5 \%$ das mortes causadas por câncer em todo o mundo. Considera-se tratamento de primeira linha o uso da quimioterapia com Gemcitabina, quimioterápico que pode ocasionar efeitos indesejáveis que impulsionaram o estudo de novas alternativas terapêuticas. Assim, destaca-se o P-MAPA, imunoterápico responsável pela ativação do sistema imune através da modulação da via inflamatória. Considerando os resultados obtidos, foi possível observar que o imunomodulador P-MAPA pode ser uma opção terapêutica mais eficiente do que a terapia de primeira escolha, a Gemcitabina. Ainda, a utilização dos dois compostos em associação permite que atuem de forma sinérgica, potencializando os resultados e permitindo, portanto, a remissão da neoplasia com maior facilidade. Assim, o desenvolvimento deste imunoterápico pode representar maior taxa de sobrevida e qualidade de vida aos pacientes, demonstrando sua importância e eficiência.

\section{Palavras-chave:}

P-MAPA, imunoterapia, câncer pancreático.

\section{Introdução}

O câncer pancreático corresponde a uma neoplasia de alta relevância mundialmente. Dentre suas apresentações, destaca-se o adenocarcinoma ductal pancreático (ADP). ${ }^{1}$ Neste, as principais alterações ocorrem nos ductos principal e acessório do pâncreas, sendo classificado de acordo com o grau de invasão histológica e apresentando-se como hiperplasia ductal, neoplasia intraepitelial pancreática (PanIN 1 a 3) ou carcinoma invasor. ${ }^{2}$ Os protocolos terapêuticos mais comumente utilizados incluem a associação da excisão cirúrgica à quimioterapia, sendo a Gemcitabina a droga de primeira escolha. ${ }^{3}$ Esta, embora eficiente, pode ser responsável pela manifestação acentuada de efeitos colaterais. Tal fato impulsiona o estudo de novas alternativas terapêuticas tais como o imunoterápico $\mathrm{P}$ MAPA (agregado polimérico anidrido fosfolinoleatopalmitoleato de amônio e magnésio). ${ }^{4}$ Desta forma, o presente projeto visou a avaliação dos efeitos imunológicos e histopatológicos do P-MAPA como tratamento único e também associado e em comparação à Gemcitabina frente o desenvolvimento do câncer pancreático; avaliando-se, portanto, a modulação da via inflamatória através das proteínas CD14, TLR2, TLR4, NF-kB, MyD88, IL-6, TNF- $\alpha$ e TGF- $\beta$.

\section{Resultados e Discussão}

Durante a primeira fase de análise obteve-se que a indução do câncer foi eficiente em 100\% dos animais desafiados, ao passo que os animais desafios e nãotratados obtiveram lesões PanIN-3 (40\%) e carcinoma invasor $(60 \%)$. Os animais tratados unicamente com Gemcitabina apresentaram lesões PanIN-1 (20\%), PanIN2 (20\%), PanIN-3 (40\%) e carcinoma invasor (20\%). A terapia com P-MAPA demonstrou a presença de hiperplasia ductal em $40 \%$ dos animais e lesões PanIN-1 (40\%) e PanIN-2 (20\%). Por fim, a associação das duas terapias permitiu que $60 \%$ dos animais obtivessem amostras normais, $20 \%$ com hiperplasia ductal e $20 \%$ com neoplasia PanIN-1. A análise imuno-histoquímica, por sua vez, permitiu a quantificação das proteínas CD14, TLR2, TLR4, NF-kB, MyD88, IL-6, TNF- $\alpha$ e TGF- $\beta$, que demonstraram-se em níveis basais em animais sadios, ao passo que foram aumentadas nos animais desafiados por DMBA, ambos resultados condizentes com a literatura. O tratamento com Gemcitabina, por sua vez, foi eficiente, embora as proteínas tenham obtido menor expressão quando na utilização da imunoterapia com P-MAPA. Por fim, a associação das duas terapias permitiu relevante redução de expressão proteica nos tecidos avaliados, obtendo-se imunomarcações mais fracas nestes tecidos, demonstrando sua maior eficiência. Desta forma, a associação terapêutica foi considerada o melhor protocolo terapêutico, já que atua reduzindo a agressividade e progressão tumoral via redução da ativação da via inflamatória crônica deflagrada pelos receptores do tipo Toll 2 e 4. Tal hipótese deriva do fato de que, ao avaliar globalmente a expressão das proteínas, foi possível notar que, de maneira geral, houve a redução da ativação dos receptores TLR2 e TLR4/CD14 e subsequentemente a ativação e migração de NF-kB para o núcleo, reduzindo significativamente o processo inflamatório deflagrado e assim contribuindo para a redução da progressão tumoral observada na análise histopatológica

\section{Conclusões}

Os resultados obtidos evidenciam que a imunoterapia com P-MAPA demonstrou-se eficiente, permitindo uma evolução potencial no tratamento do câncer pancreático e, portanto, pode contribuir para o desenvolvimento de uma nova modalidade terapêutica para a neoplasia.

\section{Agradecimentos}

Este projeto foi financiado pela Fundação de Amparo À Pesquisa do Estado de São Paulo (FAPESP), em processo de número 2018/05429-9.

\footnotetext{
${ }^{1}$ Sharma, C.; et al. Advances in diagnosis, treatment and palliation of pancreatic carcinoma: 1990-2010. World J Gastroenterol, 2011, 17(7):867-97.

${ }^{2}$ Li, D.; et al. Pancreatic cancer. Lancet, 2004, 363(9414):1049-57.

${ }^{3}$ Vicente, E.; Quijano, Y. Have the current and promising therapeutic options changed the surgeon's role in the treatment of pancreatic cancer? Revista do Colégio Brasileiro de Cirurgióes, 2017, 44:1-3.

${ }^{4}$ Favaro, W. J. et al. Effects of P-MAPA Immunomodulator on Toll-Like Receptors and p53: Potential Therapeutic Strategies for Infectious Diseases and Cancer. Infect Agent Cancer, 2012, 7(1):14.
} 